\title{
Behaviour-time budget and functional habitat use of a free-ranging European badger (Meles meles)
}

\author{
David W McClune1, Nikki J Marks ${ }^{1 *}$, Richard J Delahay ${ }^{2}$, W lan Montgomery ${ }^{1}$ and David M Scantlebury ${ }^{\text {* }}$
}

\begin{abstract}
Background: The European badger (Meles meles) is involved in the maintenance of bovine tuberculosis infection and onward spread to cattle. However, little is known about how transmission occurs. One possible route could be through direct contact between infected badgers and cattle. It is also possible that indirect contact between cattle and infected badger excretory products such as faeces or urine may occur either on pasture or within and around farm buildings. A better understanding of behaviour patterns in wild badgers may help to develop biosecurity measures to minimise direct and indirect contact between badgers and cattle. However, monitoring the behaviour of free-ranging badgers can be logistically challenging and labour intensive due to their nocturnal and semi-fossorial nature. We trialled a GPS and tri-axial accelerometer-equipped collar on a free-ranging badger to assess its potential value to elucidate behaviour-time budgets and functional habitat use.
\end{abstract}

Results: During the recording period between $16: 00$ and 08:00 on a single night, resting was the most commonly identified behaviour (67.4\%) followed by walking (20.9\%), snuffling (9.5\%) and trotting (2.3\%). When examining accelerometer data associated with each GPS fix and habitat type (occurring 2 min 30 s before and after), walking was the most common behaviour in woodland (40.3\%) and arable habitats (53.8\%), while snuffling was the most common behaviour in pasture (61.9\%). Several nocturnal resting periods were also observed. The total distance travelled was $2.28 \mathrm{~km}$.

Conclusions: In the present report, we demonstrate proof of principle in the application of a combined GPS and accelerometer device to collect detailed quantitative data on wild badger behaviour. Behaviour-time budgets allow us to investigate how badgers allocate energy to different activities and how this might change with disease status. Such information could be useful in the development of measures to reduce opportunities for onward transmission of bovine tuberculosis from badgers to cattle.

Keywords: Accelerometry, GPS, Badger, Meles meles, Mustelid, Behaviour, Biosecurity

\section{Background}

There is substantial interest in badger behaviour owing to their involvement in the transmission of Mycobacterium bovis (the causative agent of bovine tuberculosis (bTB)) to cattle [1]. Control of bTB in cattle is a major animal health issue in the UK with a cost of over $£ 100$ million in Great Britain during 2011 to 2012 and almost $£ 23$ million in Northern Ireland during 2010 to 2011 [2,3]. Although

\footnotetext{
*Correspondence: n.marks@qub.ac.uk; m.scantlebury@qub.ac.uk

1 School of Biological Sciences, Institute for Global Food Security, Queen's

University Belfast, University Road, Belfast BT7 1NN, UK

Full list of author information is available at the end of the article
}

badgers rarely interact directly with cattle on pasture, indirect interactions - such as cattle investigating pasture contaminated with badger excrement - are thought to occur more frequently [4-8]. Badgers are also known to visit farm buildings and use cattle troughs $[9,10]$. Infected badgers may display behavioural differences, as disease status has been shown to correlate with both ranging and denning behaviour with infected individuals having larger home ranges [11] and spending a greater proportion of their time occupying outlier sets [12]. There are also accounts of chronically infected badgers becoming solitary and taking up residence in farm buildings [13]. 
Therefore, a greater understanding of the behaviour of free-ranging badgers, particularly within areas of potential direct or indirect overlap with cattle, would be important when devising biosecurity measures to reduce opportunities for disease transmission. The present study reports the use of GPS and tri-axial accelerometer devices on a free-ranging European badger. Our study provides proof of principle for the utility of this technology in the construction of detailed behaviour-time budgets for this nocturnal, semi-fossorial wild carnivore.

\section{Methods}

A population of wild badgers has been the subject of an intensive long-term ecological and epidemiological study at Woodchester Park, Gloucestershire, SouthWest England. The study area consists of a mosaic of largely deciduous woodland and pasture (see [14] for detailed composition). During routine capture-markrecapture exercises [15] in January 2012, an adult female European badger (Meles meles) with a body mass of $9.0 \mathrm{~kg}$ was captured in a steel mesh live-trap and transferred to an examination facility where it was anaesthetised by intramuscular administration of two parts butorphanol tartrate (Torbugesic, Wyeth, Ontario, Canada), two parts ketamine hydrochloride (Ketaset, Wyeth, Ontario, Canada) and one part medetomidine (Domitor, Orion Corporation, Espoo, Finland) [16]. Samples of faeces, urine, and tracheal and oesophageal aspirate were collected for mycobacterial culture [17], and a sample of jugular blood was taken for gamma interferon (IFN $\gamma$ ) [18] testing and STAT-PAK serological assay (BrockTB STATPAK $^{\circ}$; Chembio Diagnostic Systems, New York, USA) [19]. A leather collar was fitted to the badger with a GPS (i-gotU GT-120; Mobile Action Technology, Inc., Taiwan) configured to record a fix once every $5 \mathrm{~min}$ and a triaxial accelerometer (X8M-3; Gulf Coast Data Concepts, LLC, Waveland, USA; recording range: $\pm 2 g$ ) set to record acceleration (and therefore behaviour) at $50 \mathrm{~Hz}$. In addition, the system temperature of the accelerometer was recorded once every $15 \mathrm{~min}$. Both devices were scheduled to record daily between 16:00 and 08:00 in order to target out-of-sett activity. The devices were attached securely to a leather collar using tesa tape (No. 4651; tesa AG, Hamburg, Germany). The $y$-axis of the accelerometer corresponded with 'surge' motion (front-back acceleration), the $x$-axis with 'sway' (left-right acceleration) and the $z$-axis with 'heave' (up-down acceleration). Following recovery from anaesthesia, the animal was released at the point of capture. After a period of approximately 1 week, traps were baited and reset to recapture the animal, after which the collar was removed and data were downloaded. Data from the first night post-release were disregarded as they are likely to have been most influenced by the trapping event. The battery of the accelerometer depleted during the third night. Thus, data described are of the complete second night starting approximately $25 \mathrm{~h}$ after release. Accelerometer data were processed using the software and decision tree from a previous validation study on a captive badger [20]. In brief, static acceleration was derived by taking a 2 -s running mean of the raw acceleration data. Dynamic acceleration was obtained by subtracting the static acceleration from the raw acceleration [21]. Vectorial dynamic body acceleration (VeDBA) was calculated as the vectorial sum of dynamic acceleration in the three axes [22]. The mean absolute dynamic acceleration, mean static acceleration, and normalised maximum amplitude by discrete Fourier transform were then extracted within a 2-s sliding window. Behaviour was classified as: resting if there was low mean absolute dynamic acceleration in each axis (less than or equal to $0.03 \mathrm{~g}$ ); snuffling (the primary mode of foraging) if there was an increase in mean static acceleration in the surge axis indicating that the badger had its nose pointing towards the ground (greater than or equal to $0.345 \mathrm{~g}$ ); and, depending on amplitude in the heave axis, walking (less than $0.664 \mathrm{~g}$ ) or trotting (greater than or equal to $0.664 \mathrm{~g}$ ) [20]. Classification values are reported as percentage (by dividing the number of data points classified as a given behaviour by the total number of points) and time engaged (by dividing the number of data points by the sampling frequency) in each behaviour. GPS traces were visualised using $\mathrm{R}$ version 3.1.3 [23]. Capture and examination of badgers at Woodchester Park is carried out under licence from Natural England and the UK Home Office and with the approval of the APHA Animal Welfare Ethical Review Body.

\section{Results}

The collared badger was negative on $M$. bovis culture, IFN $\gamma$ and STAT-PAK tests at all captures up to and including the date of collar attachment. Thus, the subject was considered to be bTB negative. The mean $( \pm \mathrm{SD})$ ambient temperature during the recording period was $4.0^{\circ} \mathrm{C} \pm 1.0^{\circ} \mathrm{C}$ (obtained from a local weather station situated approximately $4.7 \mathrm{~km}$ from the study area). There were occasional bouts of activity from 16:00 until approximately 18:00, but resting was the most common behaviour (92.6\%; collar temperature (mean $\pm \mathrm{SD}$ ): $37.2^{\circ} \mathrm{C} \pm 1.7^{\circ} \mathrm{C}$ ). The badger then became more active and briefly exited the sett at about 19:00 as trotting behaviour was observed (activity between 18:55 and 19:05: 6 min $1 \mathrm{~s}$ (60.9\%) walking, 1 min $2 \mathrm{~s}(10.6 \%)$ trotting, 2 min $34 \mathrm{~s}(26.0 \%)$ snuffling, and $14 \mathrm{~s}(2.5 \%)$ resting) and the collar temperature dropped to $14.0^{\circ} \mathrm{C}$, although no GPS fix was obtained at this point. Shortly thereafter, the badger returned to the sett and again resting was the most common behaviour with brief periods of activity (behavioural classification between 19:20 and 22:55: $26 \mathrm{~min} 18 \mathrm{~s}$ (13.1\%) walking, $2 \mathrm{~s}$ 
(0.0\%) trotting, $5 \mathrm{~min} 28 \mathrm{~s}(2.7 \%)$ snuffling, and $2 \mathrm{~h} 49 \mathrm{~min}$ $18 \mathrm{~s}(84.2 \%)$ resting; collar temperature: $34.9^{\circ} \mathrm{C} \pm 3.1^{\circ} \mathrm{C}$ ). At approximately 23:00, activity levels increased and the first GPS fix was obtained at 23:21:08. During the recording period, three distinct trips were made from setts (blue, orange, and purple tracks in Figure 1 and Additional file 1). For a detailed account of the out-of-sett behaviours associated with each GPS fix and nocturnal resting periods between each trip, see Table 1 . The final GPS fix was obtained at 02:10:27. From 03:00 until the remainder of the recording period at 08:00, the badger appeared to settle and resting was the most classified behaviour (83.4\%). The total distance travelled, calculated from all GPS fixes, was $2.28 \mathrm{~km}$. After linking the habitat types associated with each GPS fix, walking was the most common locomotory gait in all habitats (woodland: $40.3 \%$, pasture: $19.8 \%$, and arable: $53.8 \%$ ). Snuffling was the most common behaviour in pasture $(61.9 \%)$ suggesting that it was an important foraging habitat (Table 2).
Out of the total recording period, resting was the most classified behaviour (67.4\%), followed by walking (20.9\%), snuffling (9.5\%) and trotting (2.3\%). Although trotting was the least classified behaviour, it accounted for a substantial proportion (17.5\%) of the overall instantaneous VeDBA (Table 3). This VeDBA value may be a slight underestimate as particularly vigorous activity occasionally exceeded the maximum recording range of the accelerometer.

\section{Discussion}

Methods previously used to study the behaviour and movement patterns of wild badgers include direct observation and radio telemetry [24,25], camera surveillance [9], the spool-and-line technique [26,27] and magnetic localisation [28,29]. GPS and proximity logger devices have also previously been deployed on freeranging European badgers [5,7,30]. Recently, badgers have been used in captive scenarios to validate the use of accelerometers in the classification of animal

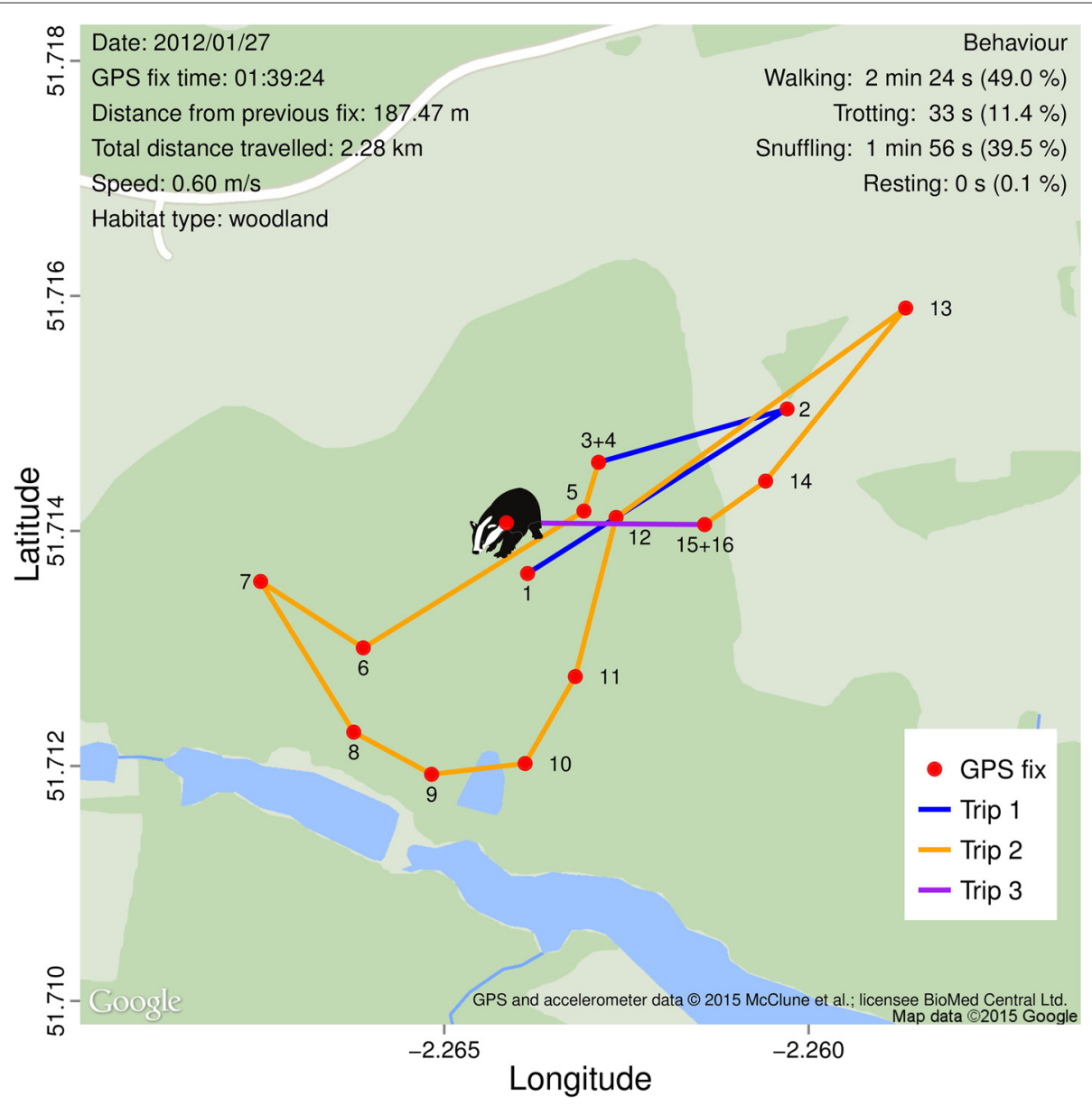

Figure 1 GPS tracks and behaviour of a free-ranging adult female European badger (Meles meles). GPS traces of three distinct trips from setts by the badger. Accelerometer derived behavioural information is also displayed (classified 2 min $30 \mathrm{~s}$ before and after the GPS fix time). The badger was considered to be inside a sett if: resting behaviour was classified, there were no GPS fixes, and there was an increase in collar temperature. See Additional file 1 for an animated version with location and associated behavioural information for each GPS fix in turn. 
Table 1 Behavioural classifications associated with GPS fixes and nocturnal resting periods

\begin{tabular}{|c|c|c|c|c|c|c|c|}
\hline Time & Fix number & Habitat type & Walking & Trotting & Snuffling & Resting & Notes \\
\hline $23: 21: 08$ & 1 & woodland & 3 min 30 s (72.4\%) & $36 \mathrm{~s}(12.5 \%)$ & $43 \mathrm{~s}(15.1 \%)$ & Os (0.0\%) & Left sett. 'Trip 1' \\
\hline 23:32:06 & 2 & pasture & 1 min $41 \mathrm{~s}(34.7 \%)$ & $1 \mathrm{~min} 44 \mathrm{~s}(35.6 \%)$ & 1 min 27 s (29.7\%) & $0 \mathrm{~s}(0.0 \%)$ & Moved into pasture \\
\hline 23:37:00 & 3 & woodland & 1 min 25 s (29.9\%) & 28 s (10.1\%) & $2 \min 51 \mathrm{~s}(60.1 \%)$ & Os $(0.0 \%)$ & $\begin{array}{l}\text { Returned to woodland. } \\
\text { Trip } 1 \text { distance travelled: } \\
475.80 \mathrm{~m} \text {, collar temperature } \\
\text { (mean } \pm \mathrm{SD} \text { ): } 9.5^{\circ} \mathrm{C} \pm 6.4^{\circ} \mathrm{C}\end{array}$ \\
\hline $\begin{array}{l}23: 37: 00 \text { to } \\
00: 05: 47\end{array}$ & & & $9 \min 25 \mathrm{~s}(35.2 \%)$ & $15 \mathrm{~s}(1.0 \%)$ & 4 min $23 \mathrm{~s}(16.4 \%)$ & $12 \min 43 \mathrm{~s}(47.5 \%)$ & $\begin{array}{l}\text { Re-entered sett. } \\
\text { Nocturnal resting period. } \\
\text { Collar temperature: } \\
16.3^{\circ} \mathrm{C} \pm 9.9^{\circ} \mathrm{C}\end{array}$ \\
\hline $\begin{array}{l}00: 05: 47 \\
00: 11: 29 \\
00: 16: 15 \\
00: 21: 07 \\
00: 26: 08 \\
00: 30: 55 \\
00: 35: 47 \\
00: 41: 22 \\
00: 50: 07\end{array}$ & $\begin{array}{l}4, \\
5, \\
6, \\
7, \\
8, \\
9, \\
10, \\
11, \\
12,\end{array}$ & woodland & $19 \min 11 \mathrm{~s}(44.9 \%)$ & $6 \min 5 \mathrm{~s}(14.2 \%)$ & $14 \min 16 \mathrm{~s}(33.4 \%)$ & $3 \min 13 \mathrm{~s}(7.5 \%)$ & $\begin{array}{l}\text { Left sett. Tracked down } \\
\text { and up the valley through } \\
\text { woodland. 'Trip 2' }\end{array}$ \\
\hline 01:02:04 & 13 & arable & 2 min 27 s (53.8\%) & $1 \mathrm{~min} 45 \mathrm{~s}(38.4 \%)$ & $21 \mathrm{~s}(7.8 \%)$ & Os $(0.0 \%)$ & $\begin{array}{l}\text { Moved across pasture to } \\
\text { arable land }\end{array}$ \\
\hline $01: 13: 35$ & 14 & pasture & $15 \mathrm{~s}(5.2 \%)$ & $3 \mathrm{~s}(1.2 \%)$ & $4 \min 39 \mathrm{~s}(93.6 \%)$ & $0 \mathrm{~s}(0.0 \%)$ & $\begin{array}{l}\text { Re-visited pasture. High } \\
\text { classification of snuffling }\end{array}$ \\
\hline $01: 18: 35$ & 15 & woodland & 55 s (19.1\%) & $44 \mathrm{~s}(15.1 \%)$ & $3 \min 11 \mathrm{~s}(65.8 \%)$ & Os $(0.0 \%)$ & $\begin{array}{l}\text { Returned to woodland. } \\
\text { Trip } 2 \text { distance travelled: } \\
1.62 \mathrm{~km} \text {, Collar temperature: } \\
9.8^{\circ} \mathrm{C} \pm 7.6^{\circ} \mathrm{C}\end{array}$ \\
\hline $\begin{array}{l}01: 18: 35 \text { to } \\
01: 34: 11\end{array}$ & & & 4 min 58 s (31.6\%) & $31 \mathrm{~s}(3.3 \%)$ & 5 min 35 s (35.5\%) & 4 min 40 s $(29.6 \%)$ & $\begin{array}{l}\text { Entered a sett, possibly } \\
\text { an outlier. Nocturnal } \\
\text { resting period. Collar } \\
\text { temperature: } 13.5^{\circ} \mathrm{C} \pm 13.4^{\circ} \mathrm{C}\end{array}$ \\
\hline $\begin{array}{l}01: 34: 11 \\
01: 39: 24\end{array}$ & $\begin{array}{l}16 \\
17\end{array}$ & woodland & $3 \min 16 s(33.7 \%)$ & 33 s (5.8\%) & $2 \min 12 \mathrm{~s}(22.8 \%)$ & $3 \min 40 \mathrm{~s}(37.8 \%)$ & $\begin{array}{l}\text { Left sett. Moved } \\
\text { back to the original point } \\
\text { of emergence. 'Trip 3', distance } \\
\text { travelled: } 187.47 \mathrm{~m} \text {, Collar } \\
\text { temperature: } 23.0^{\circ} \mathrm{C}\end{array}$ \\
\hline $\begin{array}{l}01: 39: 24 \text { to } \\
02: 10: 27\end{array}$ & & & $9 \min 6 \mathrm{~s}(30.5 \%)$ & $2 \mathrm{~s}(0.1 \%)$ & 3 min $47 \mathrm{~s}(12.7 \%)$ & $16 \min 54 \mathrm{~s}(56.7 \%)$ & $\begin{array}{l}\text { Re-entered a sett. } \\
\text { Nocturnal resting period. } \\
\text { Collar temperature: } \\
25.7^{\circ} \mathrm{C} \pm 2.5^{\circ} \mathrm{C}\end{array}$ \\
\hline $02: 10: 27$ & 18 & woodland & 17 s (7.4\%) & Os $(0.0 \%)$ & 25 s (10.4\%) & $3 \min 19 \mathrm{~s}(82.2 \%)$ & $\begin{array}{l}\text { Briefly emerged, before } \\
\text { returning to the sett. }\end{array}$ \\
\hline
\end{tabular}

Classified 2 min 30 s before and after each GPS fix.

Table 2 Summary of functional habitat use for a free-ranging European badger (Meles meles)

\begin{tabular}{llll}
\hline Behaviour & Woodland & Pasture & Arable \\
\hline Walking & $28 \min 37 \mathrm{~s}(40.3 \%)$ & $1 \min 57 \mathrm{~s}(19.8 \%)$ & $2 \min 27 \mathrm{~s}(53.8 \%)$ \\
Trotting & $8 \min 28 \mathrm{~s}(11.9 \%)$ & $1 \min 48 \mathrm{~s}(18.3 \%)$ & $1 \min 45 \mathrm{~s}(38.4 \%)$ \\
Snuffling & $23 \min 41 \mathrm{~s}(33.4 \%)$ & $6 \min 6 \mathrm{~s}(61.9 \%)$ & $21 \mathrm{~s}(7.8 \%)$ \\
Resting & $10 \min 12 \mathrm{~s}(14.4 \%)$ & $0 \mathrm{~s}(0.0 \%)$ & $0 \mathrm{~s}(0.0 \%)$ \\
\hline
\end{tabular}

Derived from tri-axial accelerometer data $2 \mathrm{~min} 30 \mathrm{~s}$ before and after each GPS fix $(n=18)$. behaviour [20,31-33]. The use of tri-axial accelerometers has also been reported on free-ranging badgers, although they were used to either gain a coarser measurement of overall activity (smoothed with a 10-min running mean) [34] or to identify basic postural changes during rest [35] rather than the classification of discrete behaviours. Future work to calibrate VeDBA with rate of oxygen consumption $\left(\mathrm{V}_{2}\right)$ by respirometry would allow specific energetic costs to be assigned to behaviours in high resolution. VeDBA (for example, Table 3) can be 
Table 3 Overall behaviour-time budget and VeDBA of four behaviours in a free-ranging European badger (Meles meles)

\begin{tabular}{|c|c|c|c|}
\hline Behaviour & Time (\%) & Total Inst. VeDBA (g) (\%) & Median VeDBA (IQR) $(g)$ \\
\hline Walking & 3 h $11 \min (20.9 \%)$ & $172,118(46.5 \%)$ & 0.231 (0.121 to 0.388$)$ \\
\hline Trotting & $20 \min 49 \mathrm{~s}(2.3 \%)$ & $64,761(17.5 \%)$ & 1.055 (0.704 to 1.275$)$ \\
\hline Snuffling & $1 \mathrm{~h} 26 \min 21 \mathrm{~s}(9.5 \%)$ & $109,553(29.6 \%)$ & 0.318 (0.179 to 0.528$)$ \\
\hline Resting & 10 h $15 \min 12$ s (67.4\%) & $23,338(6.3 \%)$ & 0.011 (0.008 to 0.015$)$ \\
\hline Overall & $15 \mathrm{~h} 13 \mathrm{~min} 24 \mathrm{~s}$ & 369,770 & 0.015 (0.010 to 0.137$)$ \\
\hline
\end{tabular}

Inst., Instantaneous.

used as a proxy for energy expenditure owing to the linear relationship of dynamic body acceleration with $\dot{\mathrm{VO}}_{2}[22,36,37]$.

When examining functional habitat use in the present study, GPS fixes were designated to a habitat type and the associated accelerometer classified behaviours were collated (similar to [38], although our implementation differs). An improvement on this method would be to incorporate dead reckoning (see [39]) to recreate the exact travel path so that all accelerometer data could be associated with a habitat type, not just those temporally linked with GPS fixes which may be sporadic under certain conditions such as tree cover or dense vegetation. We must emphasise that the present study relied on the classification thresholds defined in McClune et al. (2014) [20], which were derived from a single individual with an accuracy of $99.4 \%$ for resting, $78.7 \%$ for trotting, $77.5 \%$ for snuffling and $77.4 \%$ for walking. Parallel direct tracking (and observation as far as possible) or video footage recorded using camera traps could be used to expand upon training data sets and further assess the accuracy of these methods with respect to inter-individual variation and terrain. Classification improvements may be made by experimenting with additional algorithms such as hidden Markov models (for example, [40]). Even on the second night post-release, it is possible that the badger's behaviour was influenced by the trapping event due to lost foraging time. Nevertheless, the present study demonstrates proof of principle in the application of combined GPS and accelerometer devices to collect detailed data on the behaviour of free-ranging European badgers, and results agree with previous work, suggesting that woodland is a preferred habitat but pasture is also an important foraging area [41]. Additional behaviours that may be identifiable in badgers by accelerometry include squatmarking and defecation during latrine use from static, postural changes $[42,43]$. Specific foraging events could also be investigated in more detail (for example, [44,45]) as badgers are known to display a pronounced upward flick of the head when predating earthworms [46].

\section{Conclusions}

In the present study, we demonstrate the utility of a combined GPS and accelerometer device to collect detailed quantitative data on wild badger behaviour. The badger spent the largest proportion of time resting, followed by walking, snuffling and trotting. Behaviour also appeared to vary depending on habitat type, with walking the most common behaviour associated with GPS fixes in both woodland and arable areas, compared to snuffling on pasture. Over extended deployments, such behaviour-time and habitat use information may be of value to quantify putative bTB-induced behavioural alterations in badgers. A greater understanding of badger behaviour on and around farms, particularly in areas of potential direct or indirect overlap with livestock, could be important in the development of biosecurity measures to reduce opportunities for disease transmission.

\section{Additional file}

Additional file 1: Functional habitat use of a free-ranging European badger (Meles meles). An animation showing the time and location of each GPS fix. Information on distance travelled, speed, habitat type, and approximate points of sett entry are displayed. The corresponding accelerometer derived behaviours ( 2 min $30 \mathrm{~s}$ before and after each GPS fix time) are also shown.

\section{Abbreviations}

g: Gravitational acceleration ( $1 \mathrm{~g}=9.80665 \mathrm{~m} / \mathrm{s}^{2}$ ); bTB: bovine tuberculosis; IFN $\gamma$ : Gamma interferon; VeDBA: Vectorial dynamic body acceleration; $\dot{\mathrm{V}}_{2}$ : Rate of oxygen consumption.

\section{Competing interests}

The authors declare that they have no competing interests.

\section{Authors' contributions}

DWM performed the experiments and analysed the data. DWM, NJM, RJD, WIM, and DMS wrote the paper. All authors read and approved the final manuscript.

\section{Acknowledgements}

We are grateful to staff at the APHA's National Wildlife Management Centre, Woodchester Park, for assistance with fieldwork and trapping, and to APHA at Weybridge and Fera, York, for TB diagnostics. We are also indebted to all the farmers and landowners in the Woodchester Park study area for their co-operation. The long-term study was funded by Defra. Katie Barbour made helpful comments on the paper. David W. McClune was supported by a PhD studentship from the Department of Employment and Learning (Northern Ireland).

\section{Author details}

${ }^{1}$ School of Biological Sciences, Institute for Global Food Security, Queen's University Belfast, University Road, Belfast BT7 1NN, UK. ${ }^{2}$ National Wildlife Management Centre, Animal and Plant Health Agency, Woodchester Park, Gloucestershire GL10 3UJ, UK. 
Received: 23 December 2014 Accepted: 10 March 2015 Published online: 28 March 2015

\section{References}

1. Gortázar C, Delahay RJ, McDonald RA, Boadella M, Wilson GJ, GavierWiden $\mathrm{D}$, et al. The status of tuberculosis in European wild mammals. Mammal Rev. 2012;42(3):193-206. doi:10.1111/j.1365-2907.2011.00191.x

2. Department for Environment Food and Rural Affairs. Bovine Tuberculosis Evidence Plan. 2013. https://www.gov.uk/government/uploads/system/ uploads/attachment_data/file/221077/pb13909-evidenceplan-bovinetuberculosis.pdf.

3. NIAO. Agriculture and Rural Development Committee: Review of Bovine Tuberculosis. 2012. http://www.niassembly.gov.uk/Documents/ Agriculture-and-Rural-Development/Reviews/Bovine-Tuberculosis/ Written-Submissions/NI-Audit-Office.pdf.

4. Benham PFJ, Broom DM. Interactions between cattle and badgers at pasture with reference to bovine tuberculosis transmission. Brit Vet $J$. 1989;145(3):226-41.

5. Böhm M, Hutchings MR, White PCL. Contact networks in a wildlife-livestock host community: identifying high-risk individuals in the transmission of bovine TB among badgers and cattle. PloS ONE. 2009;4(4): 5016. doi:10.1371/journal.pone.0005016.

6. Drewe JA, O'Connor HM, Weber N, McDonald RA, Delahay RJ. Patterns of direct and indirect contact between cattle and badgers naturally infected with tuberculosis. Epidemiol Infect. 2013;141(7):1467-75. doi:10.1017/S0950268813000691.

7. Mullen EM, MacWhite T, Maher PK, Kelly DJ, Marples NM, Good M. Foraging Eurasian badgers Meles meles and the presence of cattle in pastures. Do badgers avoid cattle? Appl Anim Behav Sci. 2013;144:130-7.

8. Scantlebury M, Hutchings MR, Allcroft DJ, Harris S. Risk of disease from wild life reservoirs: badgers, cattle, and bovine tuberculosis. J Dairy Sci. 2004;87(2):330-9. doi:10.3168/jds.S0022-0302(04)73172-0.

9. Garnett BT, Delahay RJ, Roper TJ. Use of cattle farm resources by badgers (Meles meles) and risk of bovine tuberculosis (Mycobacterium bovis) transmission to cattle. Proc R Soc Lond B: Biol Sci. 2002;269(1499): 1487-91. doi:10.1098/rspb.2002.2072.

10. Tolhurst BA, Delahay RJ, Walker NJ, Ward Al, Roper TJ. Behaviour of badgers (Meles meles) in farm buildings: Opportunities for the transmission of Mycobacterium bovis to cattle? Appl Anim Behav Sci. 2009:117(1-2):103-13. doi:10.1016/j.applanim.2008.10.009.

11. Garnett BT, Delahay RJ, Roper TJ. Ranging behaviour of European badgers (Meles meles) in relation to bovine tuberculosis (Mycobacterium bovis) infection. Appl Anim Behav Sci. 2005;94(3-4):331-40. doi:10.1016/j.applanim.2005.02.013.

12. Weber N, Bearhop S, Dall SRX, Delahay RJ, McDonald RA, Carter SP. Denning behaviour of the European badger (Meles meles) correlates with bovine tuberculosis infection status. Behav Ecol Sociobiology. 2012;67(3): 471-9. doi:10.1007/s00265-012-1467-4.

13. Cheeseman CL, Mallinson PJ. Behaviour of badgers (Meles meles) infected with bovine tuberculosis. J Zool. 1981;194(2):284-9. doi:10.1111/j.1469-7998.1981.tb05780.x.

14. Delahay RJ, Carter SP, Forrester GJ, Mitchell A, Cheeseman CL. Habitat correlates of group size, bodyweight and reproductive performance in a high-density Eurasian badger (Meles meles) population. J Zool. 2006;270(3):437-47. doi:10.1111/j.1469-7998.2006.00165.x.

15. Delahay RJ, Walker N, Smith GS, Wilkinson D, Clifton-Hadley RS, Cheeseman CL, Tomlinson AJ, Chambers MA. Long-term temporal trends and estimated transmission rates for Mycobacterium bovis infection in an undisturbed high-density badger (Meles meles) population. Epidemiol Infect. 2013;141(7):1445-56. doi:10.1017/S0950268813000721.

16. de Leeuw ANS, Forrester GJ, Spyvee PD, Brash MGI, Delahay RJ. Experimental comparison of ketamine with a combination of ketamine, butorphanol and medetomidine for general anaesthesia of the Eurasian badger (Meles meles L.) Vet J. 2004;167(2):186-93. doi:10.1016/S1090-0233(03)00113-8.

17. Clifton-Hadley RS, Wilesmith JW, Stuart FA. Mycobacterium bovis in the European badger (Meles meles): epidemiological findings in tuberculous badgers from a naturally infected population. Epidemiol Infect. 1993;111(1):9-19.

18. Dalley $D$, Davé $D$, Lesellier $S$, Palmer $S$, Crawshaw T, Hewinson RG, et al. Development and evaluation of a gamma-interferon assay for tuberculosis in badgers (Meles meles). Tuberculosis. 2008;88(3):235-43. doi:10.1016/j.tube.2007.11.001.

19. Greenwald R, Esfandiari J, Lesellier S, Houghton R, Pollock J, Aagaard C, et al. Improved serodetection of Mycobacterium bovis infection in badgers (Meles meles) using multiantigen test formats. Diagn Microbiol Infect Dis. 2003;46(3):197-203. doi:10.1016/S0732-8893(03)00046-4.

20. McClune DW, Marks NJ, Wilson RP, Houghton JDR, Montgomery IW, McGowan NE, et al. Tri-axial accelerometers quantify behaviour in the Eurasian badger (Meles meles): towards an automated interpretation of field data. Anim Biotelemetry. 2014;2(5):. doi:10.1186/2050-3385-2-5.

21. Shepard ELC, Wilson RP, Halsey LG, Quintana F, Gómez Laich A, Gleiss $A C$, et al. Derivation of body motion via appropriate smoothing of acceleration data. Aquatic Biol. 2008;4:235-41. doi:10.3354/ab00104.

22. Qasem L, Cardew A, Wilson A, Griffiths I, Halsey LG, Shepard ELC, et al. Tri-axial dynamic acceleration as a proxy for animal energy expenditure; should we be summing values or calculating the vector? PIOS ONE. 2012;7(2):31187. doi:10.1371/journal.pone.0031187.

23. R Core Team. R: A Language and Environment for Statistical Computing Vienna, Austria: R Foundation for Statistical Computing; 2015. http:// www.R-project.org/.

24. Kruuk H. Spatial organization and territorial behaviour of the European badger Meles meles. J Zool. 1978;184(1):1-19. doi:10.1111/j.1469-7998.1978.tb03262.x.

25. Roper TJ, Ostler JR, Schmid TK, Christian SF. Sett use in European badgers Meles Meles. Behaviour. 2001;138(2):173-87. doi:10.1163/15685390151074366.

26. Hawkins CE, Macdonald DW. A spool-and-line method for investigating the movements of badgers, Meles meles. Mammalia. 1992;56:322-5.

27. Brown J, Harris S, Cheeseman CL. The development of field techniques for studying potential modes of transmission of bovine tuberculosis from badgers to cattle In: Hayden TJ, editor. The Badger. Dublin: Royal Irish Academy; 1993. p. 139-153.

28. Markham A, Trigoni N, Macdonald DW, Ellwood SA. Underground localization in 3-D using magneto-inductive tracking. IEEE Sensors J. 2012;12(6):1809-16. doi:10.1109/JSEN.2011.2178064.

29. Noonan MJ, Markham A, Newman C, Trigoni N, Buesching CD, Ellwood $\mathrm{SA}$, et al. A new magneto-inductive tracking technique to uncover subterranean activity: What do animals do underground? Methods Ecol Evol. 2015

30. Brendel C, Helder R, Chevallier D, Zaytoon J, Georges J-Y, Handrich Y. Testing a Global Positioning System on free-ranging badgers Meles meles. Mammal Notes. 2012;4:1-5.

31. Gao L, Campbell HA, Bidder OR, Hunter J. A Web-based semantic tagging and activity recognition system for species' accelerometry data. Ecol Inform. 2013;13:47-56. doi:10.1016/j.ecoinf.2012.09.003.

32. Campbell HA, Gao L, Bidder OR, Hunter J, Franklin CE. Creating a behavioural classification module for acceleration data: Using a captive surrogate for difficult to observe species. J Experimental Biol. 2013089805. doi:10.1242/jeb.089805.

33. Bidder OR, Campbell HA, Gómez-Laich A, Urgé P, Walker J, Cai Y, et al. Love thy neighbour: automatic animal behavioural classification of acceleration data using the K-Nearest neighbour algorithm. PLOS ONE. 2014;9(2):88609. doi:10.1371/journal.pone.0088609.

34. Noonan MJ, Markham A, Newman C, Trigoni N, Buesching CD, Ellwood $S A$, et al. Climate and the individual: inter-annual variation in the autumnal activity of the European badger (Meles meles). PLOS ONE. 2014;9(1):83156. doi:10.1371/journal.pone.0083156.

35. Shepard ELC, Wilson RP, Quintana F, Gómez Laich A, Liebsch N, Albareda DA, et al. Identification of animal movement patterns using tri-axial accelerometry. Endangered Species Res. 2008;10:47-60. doi:10.3354/esro0084.

36. Wilson RP, White CR, Quintana F, Halsey LG, Liebsch N, Martin GR, et al Moving towards acceleration for estimates of activity-specific metabolic rate in free-living animals: the case of the cormorant. J Anim Ecol. 2006;75(5):1081-90. doi:10.1111/j.1365-2656.2006.01127.x.

37. Halsey LG, Shepard ELC, Quintana F, Gomez Laich A, Green JA, Wilson RP. The relationship between oxygen consumption and body acceleration in a range of species. Comp Biochem Physiol. Part A, Mol Integr Physiol. 2009;152(2):197-202. doi:10.1016/j.cbpa.2008.09.021.

38. Berger A, Dettki $H$, Urbano F. Deciphering animals' behaviour: joining GPS and activity data In: Urbano F, Cagnacci F, editors. Spatial Database 
for GPS Wildlife Tracking Data: a Practical Guide to Creating a Data Management System with PostgreSQL/PostGIS and R. Cham: Springer; 2014. p. 231-244. Chap. 12. doi:10.1007/978-3-319-03743-1.

39. Wilson RP, Shepard ELC, Liebsch N. Prying into the intimate details of animal lives: use of a daily diary on animals. Endangered Species Res. 2008:4:123-37. doi:10.3354/esr00064.

40. Lim D, Park C, Kim N. H, Kim S-H, Yu YS. Fall-detection algorithm using 3-axis acceleration: combination with simple threshold and hidden Markov model. J Appl Math. 2014;2014:1-8. doi:10.1155/2014/896030.

41. Kruuk H. Foraging and spatial organisation of the European badger, Meles meles L. Behav Ecol Sociobiol. 1978;4(1):75-89. doi:10.1007/BF00302562.

42. Kruuk H, Gorman M, Leitch A. Scent-marking with the subcaudal gland by the European badger, Meles meles L. Anim Behav. 1984;32(3):899-907.

43. Stewart PD, MacDonald DW, Newman C, Tattersall FH. Behavioural mechanisms of information transmission and reception by badgers, Meles meles, at latrines. Anim Behav. 2002;63(5):999-1007. doi:10.1006/anbe.2001.1990.

44. Carroll G, Slip D, Jonsen I, Harcourt R. Supervised accelerometry analysis can identify prey capture by penguins at sea. J Exp Biol. 2014:217(24): 4295-4302.

45. Viviant $M$, Monestiez $P$, Guinet C. Can we predict foraging success in a marine predator from dive patterns only? Validation with prey capture attempt data. PloS ONE. 2014;9(3):88503. doi:10.1371/journal.pone.0088503.

46. Macdonald D. W. The red fox, Vulpes vulpes, as a predator upon earthworms, Lumbricus terrestris. Zeitschrift für Tierpsychologie. 1980;52(2):171-200

\section{Submit your next manuscript to BioMed Central and take full advantage of:}

- Convenient online submission

- Thorough peer review

- No space constraints or color figure charges

- Immediate publication on acceptance

- Inclusion in PubMed, CAS, Scopus and Google Scholar

- Research which is freely available for redistribution 